\title{
Mechanisms for characterizing kinds and classes
}

\section{Sandeep Prasada}

\section{OpenEdition}

\section{Journals}

Electronic version

URL: http://journals.openedition.org/rlv/2058

DOI: $10.4000 /$ rlv.2058

ISSN: 1958-9239

\section{Publisher}

Presses universitaires de Vincennes

\section{Printed version}

Date of publication: 1 September 2012

Number of pages: $45-62$

ISBN: 978-2-84292-350-1

ISSN: 0986-6124

\section{Electronic reference}

Sandeep Prasada, « Mechanisms for characterizing kinds and classes », Recherches linguistiques de Vincennes [Online], 41 | 2012, Online since 01 September 2014, connection on 01 May 2019. URL : http://journals.openedition.org/rlv/2058; DOI : 10.4000/rlv.2058 


\title{
Ariel COHEN
}

\section{Ben-Gurion University of the Negev}

\section{GENERICS AS MODALS}

\begin{abstract}
A common view of generics is that they express universal quantification over normal individuals. I argue against this approach, and provide evidence that the quantification is neither universal nor over normal individuals.

Regarding universality, generics fail standard tests for universal quantification. As an alternative, I propose that generics express measures of high probability. I formalize this notion using a modal extension of first order probability logic, and demonstrate how this system can account for embedded generics and inference with generics.

As for normality, I contrast it with another notion, that of uniformity: generics are evaluated with respect to worlds whose future resembles their past. Using standard substitution intensionality tests, I demonstrate that generics are evaluated with respect to uniform, rather than normal worlds.

The end result is that a generic such as Birds fly does not mean "All normal birds fly"; rather, it means that the probability for a randomly chosen bird to fly is high, and this tendency is expected to continue.
\end{abstract}

\section{KEYWORDS}

Generics, modality, normality, uniform ordering source, metaphysical modal base, probability, inference, embedded generics. 


\section{The paradox of generics}

Generics are both more and less powerful than universals. They are more powerful, because they are lawlike: (1a) may be true as a contingent fact, but (1b) will not be true unless a law is enacted, requiring Supreme Court judges to have a prime Social Security number.

a. All Supreme Court judges have a prime Social Security number.

b. Supreme Court judges have a prime Social Security number.

But generics are also less powerful than universals, because they tolerate exceptions: (2a) is false, while (2b) is true.

(2) a. All birds fly.

b. Birds fly.

This paradox seems to be at the core of the problem of genericity. How can we solve it?

To solve the first problem, it is often proposed that generics are modal (Dahl 1975). Thus, (1a) is about actual Supreme Court judges, but (1b) is about possible Supreme Court judges. This is why (1a), but not (1b), can hold of a temporary, contingent generalization. But if generics are modal, what sort of modals are they?

In this paper I propose an answer to this question. I the next section I present a widely held view of generics, the "all normal" approach. In section 3 I consider whether, as the word "all" indicates, generics are really universal, or express probability judgments, as I suggest in section 4. Probabilistic accounts of generics have been subjected to various criticisms, especially regarding the ways they handle inference and embedded generics. I propose a theory that overcomes these difficulties. In the following section I proceed to examine whether generics really are about "normal" worlds, and conclude that they are not. Instead, I propose an account of generics as probability judgments over uniform worlds. Section 6 summarizes the main conclusions of the paper.

\section{The "all normal" approach}

Modality is characterized by three components (Kratzer 1981):

1. A modal base: essentially, the set of accessible worlds

2. A modal force: universal, existential, or perhaps something in between

3. An ordering source: roughly, a relation on worlds, s.t. $w_{1} \leq w_{2}$ indicates that $w_{1}$ is "better", in some sense, than $w_{2}$.

A widely held view (references too numerous to mention, but see Greenberg's article, this volume) is that generics express quantification over "all normal" 
individuals. The idea is that (2b) can be paraphrased as "All normal birds fly". This view leads to the following specification of generics, in terms of the three components of modality:

1. The modal base is, in fact, rarely discussed by proponents of this approach, but it is presumably circumstantial.

2. The modal force is clearly a universal.

3. The ordering source is stereotypical: $w_{1} \leq w_{2}$ means that $w_{1}$ is closer to the stereotypical ideal than $w_{2}$.

Thus, the meaning of ( $2 \mathrm{~b}$ ) can be expressed, somewhat inaccurately, as follows: "In all normal worlds, all birds fly."

This theory solves the first problem, i.e. accounts for the fact that generics are lawlike: since it is not an essential requirement for Supreme Court judges to have prime Social Security numbers, in normal worlds they may have composite (non-prime) Social Security numbers.

But the theory also solves the second problem, namely the fact that generics tolerate exceptions: this is because exceptions are considered abnormal instances. Thus, penguins don't fly, hence constitute exceptions, but that does not falsify (2b), because they are somehow abnormal.

This theory, then, solves both sides of the paradox at one fell swoop, which explains its attraction. But is it correct?

The "all normal" theory assumes a definition of normality, according to which, for example, non-flying birds are abnormal. But what does it mean to be abnormal? What is abnormal about the penguin? It is a bird just like any other bird, perfectly adapted to its environment, so why would we want to say that it is abnormal?

Of course, we cannot define normal birds as birds that fly, for then (2b) becomes trivial: it would simply say that all birds that fly, fly. Hence, a noncircular definition of normality is necessary. But despite much work on the "all normal" theory, no such definition seems to be forthcoming.

In addition to this conceptual problem, the "all normal" approach suffers from substantial empirical difficulties. This view constitutes of two major claims: one is that the modal force is universal, and the other is that the ordering source is stereotypical. Let us examine each one of these claims in turn.

\section{Is the modal force universal?}

There are several acknowledged tests for universal (or negatively universal) quantifiers. We can use them to determine whether the modal force is universal.

The first test involves the adverb absolutely, which can only modify universals. Thus, (3a) is fine, whereas (3b) is bad. 
(3) a. Absolutely everyone/nobody was there.

b. *Absolutely some/few/three/many/most people were there.

Generics do not behave like universals: (3c) is bad.

c. *Absolutely birds fly.

The second test makes use of exceptive phrases, which allow only universal or negatively universal quantifiers (Moltmann 1995; Zuber 1998):

a. Every/No bird except for Tweety is sad.

b. *Some/Few/Three/Many/Most birds except for Tweety are sad.

Again, generics pattern with the non-universal, rather than universal, quantifiers:

c. *Birds except for Tweety/penguins fly. ${ }^{1}$

The third test concerns even which also combines only with universal quantifiers (Zuber 2004):

a. Every bird, even Tweety, is sad.

b. No bird, not even Tweety, is sad.

c. *Some/Few/Three/Many/Most birds, even Tweety, are sad.

Once again, generics pattern with the non-universal quantifiers, and cannot combine with even:

d. *Birds, even Tweety/penguins have wings.

The fourth test was not originally developed as a test for universal quantification, but makes use of an interesting property of speech acts, discussed by Krifka (2001). He notes that (6) is ambiguous

(6) What did everyone bring to the party?

Under one reading, (6) asks which $\mathrm{x}$ is such that everyone brought $\mathrm{x}$ to the party. A possible answer can be: Beer. Under the second reading, (6) asks, for each individual $\mathrm{y}$, what y brought to the party. A possible answer would be: Mary brought beer, John brought white wine, Fred brought cookies... ${ }^{2}$

Krifka notes that only universal quantifiers are ambiguous in this way. If we replace the universal with a different quantifier, we get only the first type of interpretation. Thus, (7) can only receive an answer such as Beer, but not Mary brought beer, John brought white wine, Fred brought cookies...

(7) What did some/few/three/many/most people bring to the party?

1. This sentence is improved with comma intonation preceding except, but this kind of intonation also improves (4b).

2. Krifka notes that (6) has yet a third reading, which does not concern us here. 
When we test generics, they, once again, do not behave like universals: an acceptable answer to (8) is Honey; but the following is not a felicitous answer: Pooh likes to eat honey, Teddy likes to eat meat, Yogi like to eat everything...

(8) What do bears like to eat?

Based on all these tests, we must conclude that the modal force of generics is not universal: (2b) simply cannot mean All normal birds fly.

One might suppose that this is not such a significant setback. Perhaps, instead of a universal quantifier, we just use a different one, say most. Then (2b) would mean Most normal birds fly. However, since generics are assumed to be modal, it is not clear how to interpret this. How does one define most over infinitely many possible worlds?

\section{Probability}

\subsection{Probability as a measure function over worlds}

In order to define a non-universal quantifier over possible worlds, we need some measure function over possible worlds. A natural choice suggests itself. In fact, it has already been suggested by Schubert and Pelletier (1989). ${ }^{3}$ They propose that the generic quantifier is most, and that it quantifies over pairs of worlds and individuals, and explain:

"most" is to be interpreted in terms of some probability distribution favouring worlds $w^{\prime}$ similar to $w$ [the actual world], with regard to the "inherent" or "essential" nature of things (p. 259-260)

That is to say: Schubert and Pelletier propose a probability function that respects the stereotypical ordering source. Hence, $(2 b)$ is interpreted as saying that the probability that a normal bird flies is high.

It should be emphasized that the use of probability is not essential, and some other measure function might perhaps have done just as well. However, probability has the enormous advantage that it has been heavily studied for several centuries, and there is a wealth of useful observations, techniques, and theorems regarding probability.

However, it has been argued that probability is not an appropriate tool for dealing with generics. Let us consider some of these arguments.

3. It must be noted, however, that this was not the main point of their paper. 


\subsection{Probability and inference}

Let us suppose that the logical form of the generic As are $B s$ is gen $[\mathrm{A}(\mathrm{x})][\mathrm{B}(\mathrm{x})]$, so that the logical form of $(2 \mathrm{~b})$ is $\operatorname{gen}_{\mathrm{x}}[\operatorname{bird}(\mathrm{x})][\mathrm{fly}(\mathrm{x})]$. An important question in the study of generics is this: when can we conclude one generic from another? For example, consider the following general inference pattern:

$$
\operatorname{gen}_{x}[A(x)][B(x)] \Rightarrow \operatorname{gen}_{x}[A(x) \wedge C(x)][B(x)]
$$

The question is: for which properties $\mathrm{C}$ is the inference valid?

It has been argued (e.g., Pearl 1988) that probabilistic theories cannot answer this question satisfactorily. Pearl himself proposes that the inference is valid if we know that $\operatorname{gen}_{\mathrm{x}}[\mathrm{A}(\mathrm{x})][\mathrm{C}(\mathrm{x})]$. However, this would get us too few inferences. For example, we will not be able to conclude from the truth of $(2 b)$ that red birds fly, because (9) is not true.

(9) Birds are red.

But surely this is counterintuitive.

Pelletier and Asher (1997) propose a different solution, which is based on the idea of defeasible strengthening of the antecedent. They argue that the inference pattern in question is always valid, unless it is defeated, i.e. unless we know that

$$
\operatorname{gen}_{x}[A(x) \wedge C(x)][\neg B(x)] .
$$

However, this move would get too many inferences. For example, suppose we don't know whether (10) is true or not.

Injured birds do not fly.

Then, according to Pelletier and Asher, we must conclude:

$$
\text { Injured birds fly. }
$$

But we clearly shouldn't: it may be that (10) or (11) is true, depending on the nature and extent of the common injuries that birds suffer.

How does probability fare? In a later paper, Pearl (1991) admits:

I have speculated that this [phenomenon] is more in line with the rules of [Pearl's theory] than with those of "support" or "majority" logics [i.e., probability logic]. I am now in the opinion that this agreement is more reflective of tacit assumptions of independence.

The idea is that we can conclude that red birds fly on the basis of the truth of (2b), and that's because the properties of being red and flying are independent of each other. However, we cannot conclude from (2b) that injured birds fly, 
and that's because being injured and flying are clearly not independent of each other.

To represent these facts, we can use the mathematical notion of conditional independence. Two properties, $\alpha$ and $\beta$, are conditionally independent given $\mathrm{k}$ if:

$$
\mathrm{P}(\alpha \wedge \beta \mid \mathrm{k})=\mathrm{P}(\alpha \mid \mathrm{k}) \times \mathrm{P}(\beta \mid \mathrm{k})
$$

It can easily be shown that if red and fly are conditionally independent given bird, the inference is valid:

$$
\mathrm{P}(\mathbf{f l y} \mid \text { bird } \wedge \text { red })=\mathrm{P}(\mathbf{f l y} \mid \text { bird })
$$

\subsection{Reasoning with exceptions}

Another important question is the influence of exceptions on inferences. For example, suppose we believe (12a-c); can we conclude (12d)?
a. Mammals bear live young.
b. Mammals have a uterus.
c. Platypuses don't bear live young.
d. Platypuses have a uterus.

According to the "all normal" approach (see, e.g., Pelletier and Asher 1997), we shouldn't: (12c) has demonstrated that platypuses are abnormal; but (12b) is only about normal mammals, hence we are not licensed to conclude that platypuses have a uterus.

This appears to be a desirable result; indeed, platypuses do not have a uterus. But now consider, instead of (12b) and (12d), the following:

$$
\begin{aligned}
& b^{\prime} \text {. Mammals have hair. } \\
& d^{\prime} \text {. Platypuses have hair. }
\end{aligned}
$$

For the same reason, the "all normal" approach predicts that we cannot conclude that platypuses have hair, since $\left(12 b^{\prime}\right)$ is, presumably, only about normal mammals. But this is intuitively wrong.

The crucial factor, once again, appears to be conditional independence. Bearing live young and having a uterus are not independent given the property of being a mammal, hence (12d) does not follow. But bearing live young and having hair are independent given the property of being a mammal, hence $\left(12 d^{\prime}\right)$ does follow. The probabilistic approach, far from being unable to handle such inferences, in fact captures them naturally without the need for additional assumptions: conditional independence is an integral part of the theory of probability. 


\subsection{Embedded generics}

Embedded generics are sometimes claimed to pose a problem for probabilistic accounts of generics. Consider (13), for example.

Movies that critics love are boring.

According to the probabilistic approach, (13) means that a movie that a critic is likely to love is likely to be boring; hence the interpretation of (13) calls for higher order probability. How is it to be interpreted?

It is sometimes suggested that higher order probability is interpreted epistemically (Gaifman 1988), but this won't do here: generics, embedded or not, have objective truth conditions.

However, higher order probabilities do not have to be epistemic: they can get a natural objective interpretation. Suppose in some country the national mint is very old and in bad shape, and $80 \%$ of coins manufactured there are crooked. Then (14) is true.

(14) A coin manufactured in this mint is likely to be crooked.

This is a statement of higher order probability:

$\mathrm{P}(\mathrm{P}($ a coin manufactured in this factory comes up "heads" $) \neq 0.5))$ is high

In words, (14) means the following: pick at random a coin manufactured in this mint; it is likely that the probability that it comes up heads is not 0.5 . Note that both probabilities are objective, not epistemic.

\subsection{Probability logic}

In previous work (Cohen 1999), I proposed that probability applies at the level of interpretation. That is to say, the logical form of (2b) is gen $[\operatorname{bird}(\mathrm{x})][\mathbf{f l y}(\mathrm{x})]$, which is true iff $\mathrm{P}(\mathbf{f l y} \mid \mathbf{b i r d})>0.5 .{ }^{4}$ But in order to account for embedded generics, probabilities ought to be introduced at the level of logical form - hence the need for a logic of probability.

I will follow the logics of Baachus (1990) and Halpern (1990). ${ }^{5}$ First order logic is augmented with arithmetic operators, and with square brackets, whose intended interpretation is probability.

4. It might seem that 0.5 is too low a threshold, and that generics are much closer to universals, so a higher number is necessary. However, 0.5 , coupled with the presupposition that the domain is homogeneous, suffices to bring about this quasi-universal effect (see Cohen 1999 for the details). At any rate, in this paper nothing hinges on the value of 0.5, and the reader is free to assign a higher number if it seems more appropriate.

5. These logics are different, but for our purpose we can treat them as one. 
Unconditional probability is represented as, for example: $[\operatorname{even}(\mathrm{x})]_{x}$ $=0.5$. This means that the probability that some individual is even is 0.5 . Conditional probability is represented as, for example: $[\mathrm{fly}(\mathrm{x}) \mid \operatorname{bird}(\mathrm{x})]_{\mathrm{x}}>$ 0.5 . This says that the probability that something flies, given that it is a bird, is greater than 0.5 .

Formulas are evaluated with respect to a structure $M=\langle O, \theta, \mu\rangle$, where $O$ is a set of individuals - the domain; $\theta$ is an interpretation function, defined as usual (except for probabilities, to be discussed anon), and $\mu$ is a discrete probability function on $O$.

The probability function $\mu$ is extended to subsets of the domain as follows:

for every $A \subseteq O, \mu(\mathrm{A})=\underset{\mathrm{a} \in A}{\times} \mu(\mathrm{a})$.

For every expression $\alpha$, structure $M$, and assignment function $v$ :

$$
[\alpha]^{(\mathrm{M}, v)}=\mu(\{\mathrm{a}:(M, v[\mathrm{a} / \mathrm{x}]) \vDash \alpha\})
$$

This definition can be straightforwardly extended to multiple variables, using product measures.

The meaning of conditional probability can now be defined in the normal way:

$$
[\alpha \mid \beta]_{x} \times[\beta]_{x}=[\alpha \wedge \beta]_{x} .
$$

There is, however, an obvious problem with this definition, if we want to apply it to generics: it is extensional, while generics, as we have seen, are intensional. In order to solve this problem, we can intensionalize the definition, by making the domain, instead of a set of individuals, a set of pairs of worlds and individuals, following Schubert and Pelletier (1989; $c f$. Gallin 1975): $O=$ $W \times D$.

The interpretation function $\theta$ is now, of course, relativized to worlds. The probability function $\mu$ is now defined on pairs of worlds and individuals. We may require $\mu$ to respect the stereotypical ordering source: if $w_{1}$ is more normal than $w_{2}$, then, for all $\mathrm{d} \in \mathrm{D}, \mu\left(w_{1}, \mathrm{~d}\right) \geq \mu\left(w_{2}, \mathrm{~d}\right) .{ }^{6}$ Of course, since $\mu$ is discrete, all except for a denumerable number of worlds will have zero probability.

Now (2b) has the following logical form: $[\mathrm{fly}(\mathrm{x}) \mid \operatorname{bird}(\mathrm{x})]_{\mathrm{x}}>0.5$ Its interpretation is, roughly: the probability that $\mathrm{x}$ flies in $\mathrm{w}$, given that $\mathrm{w}$ is a normal world and $\mathrm{x}$ is a bird, is high.

6. We could also place additional constraints on $\mu$. For example, Kratzer (2009) requires $\mu$ to respect her constraint of comparative possibility. 
We can now provide a natural account of embedded generics. Consider (13), repeated below as (13a). Its logical form is (13b) which, in probability logic, becomes (13c).

a. Movies that critics love are boring.

b. $\operatorname{gen}_{\mathrm{x}}\left[\operatorname{movie}(\mathrm{x}) \wedge \operatorname{gen}_{\mathrm{y}}[\operatorname{critic}(\mathrm{y})][\operatorname{love}(\mathrm{y}, \mathrm{x})]\right][\operatorname{boring}(\mathrm{x})]$

c. $\left[\operatorname{boring}(\mathrm{x}) \mid \operatorname{movie}(\mathrm{x}) \wedge[\operatorname{love}(\mathrm{y}, \mathrm{x}) \mid \operatorname{critic}(\mathrm{y})]_{\mathrm{y}}>0.5\right]_{\mathrm{x}}>0.5$

The interpretation of (13) is that the probability that $\mathrm{x}$ is boring in $\mathrm{w}$ is high, given that $\mathrm{w}$ is normal and $\mathrm{x}$ is a movie s.t. the probability that $\mathrm{y}$ loves $\mathrm{x}$ in $\mathrm{w}^{\prime}$ is high, given that $\mathrm{w}^{\prime}$ is normal and $\mathrm{y}$ is a critic. While this is a mouthful, it nicely captures the meaning of the sentence, assuming that the ordering source is stereotypical.

\subsection{Generic comparisons}

Treating embedded generics in this way can help solve a thorny problem, involving generic comparisons (Cohen 1996; Nickel 2010). Consider the following perfectly natural sentence:

(15) Girls do better than boys in grade school.

The "all normal" approach faces a problem here, since (15) clearly does not mean that all normal female pupils do better than all normal male pupils.

Nickel (2010) attempts to solve this problem, by proposing, essentially, that (15) expresses a number of generalizations over different subsets of the pupil population. According to him, (15) means something like: All normal excellent girls do better than all normal excellent boys, all normal ok girls do better than all normal ok boys, all normal weak girls do better than all normal weak boys....

However, Nickel's proposal leads to incorrect predictions. Suppose there are few weak girls, but they are weaker than all the boys; most girls are excellent, and better than all the boys. Then (15) is true, but it is predicted false according to Nickel's account.

In earlier work (Cohen 1996) I suggested that generic comparisons express quantification over pairs. For example, (16) says that "most" 7 pairs $\langle\mathrm{x}, \mathrm{y}\rangle$ s.t. $\mathrm{x}$ is a dog and $\mathrm{y}$ is a cat are such that $\mathrm{x}$ is bigger than $\mathrm{y}$.

Dogs are bigger than cats.

However, now I am of the opinion that although this reading may be available, it is not the dominant one.

7. Most is, of course, interpreted probabilistically, as above. 
Consider, for example, a situation where one third of the dogs are huge, and bigger than all cats; while two thirds of the cats are bigger than the rest of the dogs. This situation is depicted in figure 1 .
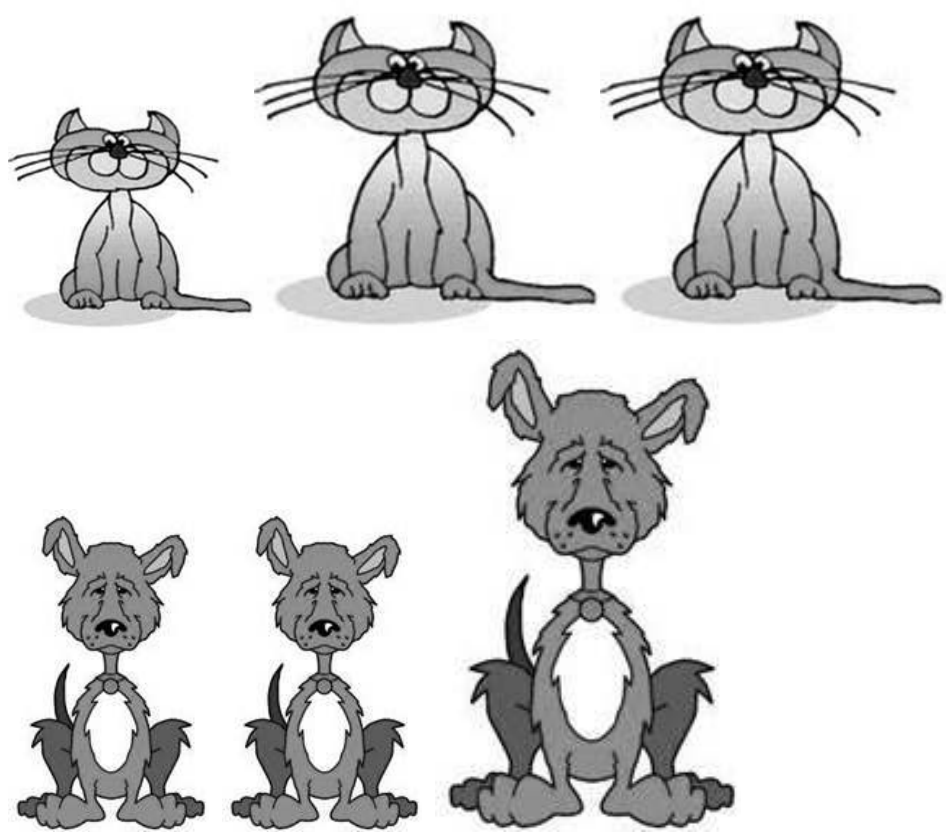

Figure 1: Cats vs dogs

Given this scenario, (16) is false, although in most pairs (5 out of 9) the dog is bigger than the cat. Intuitively, the reason is that most dogs are not bigger than most cats.

Now consider the situation depicted in figure 2.

This time, one third of the cats is bigger than all dogs, but the rest are smaller than two thirds of the dogs. Now (16) is true, although in most pairs (5 out of 9) the dog is not bigger than the cat. But again note that most dogs are bigger than most cats, which, intuitively, accounts for this judgment.

These interpretations of generic comparisons can be accounted for in a natural way if we take them to be embedded generics. Specifically, the idea is that (16) means that "most" dogs are bigger than "most" cats. Formally, its logical form is

$$
\operatorname{gen}_{x}[\operatorname{dog}(x)]\left[\operatorname{gen}_{y}[\operatorname{cat}(y)][\operatorname{bigger}(x, y)]\right] .
$$


In our logic of probability, we get

$$
\left[[\operatorname{bigger}(\mathrm{x}, \mathrm{y}) \mid \operatorname{cat}(\mathrm{y})]_{\mathrm{y}}>0.5 \mid \operatorname{dog}(\mathrm{x})\right]_{\mathrm{x}}>0.5 \text {. }
$$

Thus, (16) means that a randomly chosen dog is likely to be such that a randomly chosen cat is likely to be smaller than it. This cumbersome paraphrase captures the intended interpretation.
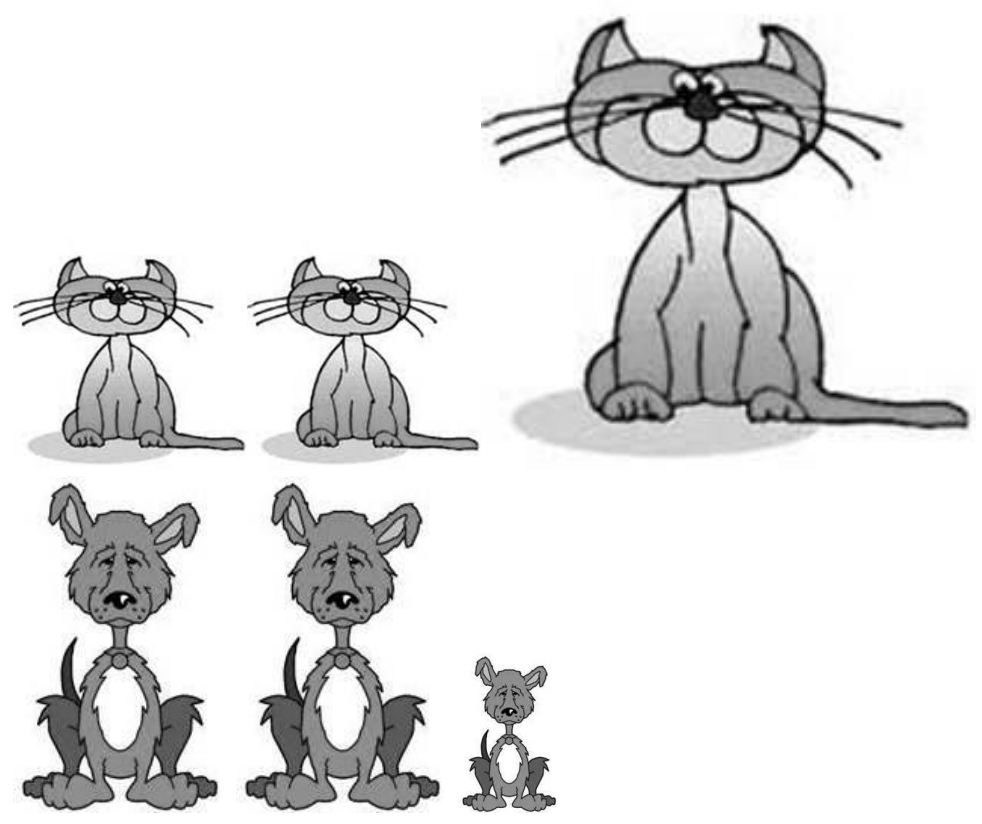

Figure 2: Cats vs dogs

\section{Is the ordering source stereotypical?}

\subsection{Theoretical considerations}

We have seen evidence that the modal force of generics is not a universal, and that it is best represented as a probability measure. Recall that the modal force is only one leg of the "all normal" approach; the other leg is the claim that the ordering source is stereotypical. These two claims are orthogonal: one can agree that the modal force is not a universal, yet still maintain that the ordering source is stereotypical. ${ }^{8}$ Yet, such a stance would have unappealing consequences.

8. Or remain unconvinced by the arguments above, and still maintain that the modal force is a universal, yet deny that the ordering source is stereotypical. 
Recall that normality was introduced in the first place to account for the problem of exceptions: exceptions are presumed to be abnormal, while generics only quantify over normal individuals. But if, indeed, the modal force is less than a universal, exceptions arise naturally, simply by the nature of nonuniversal quantification. If (2b) means something like "Most normal birds fly", then naturally this is compatible with the fact that some normal birds do not fly. Hence there is no need to make the problematic stipulation that penguins are somehow abnormal, and the notion of normality is unnecessary.

In fact, the notion of normality cannot explain exceptions: something can be normal, yet constitute an exception. This can be seen directly in the case of adverbs of quantification (Q-adverbs).

Q-adverbs, like generics, are lawlike:

(17) Supreme Court judges usually/often/sometimes/seldom have a prime Social Security number.

Sentence (17), just like (1b), is odd, because there is no law relating to the Social Security number of judges. However, Q-adverbs (except for always) are clearly not universal.

One might want to propose that Q-adverbs quantify over normal individuals, with a non-universal modal force. But then (18) would mean that some normal birds are incapable of flying.

Birds are sometimes incapable of flying.

Since (18) is true, it follows that exceptions can be normal. Hence, the notion of normality cannot account for exceptions, which was the sole reason for introducing it in the first place.

We can conclude that the "all normal" theory fails, on both its claims. The quantifier is not "all", but is rather a probability measure, and the idea of "normal" cannot account for exceptions.

There are, in fact, not only theoretical considerations, but also empirical evidence against the normality approach. This evidence is seen most clearly when we compare the normality approach with an alternative.

\subsection{Uniform worlds}

We have seen that the modal force of generics is a probability measure. How do we get the value of this probability? In real life, statisticians extrapolate probabilities from past events. This is a case of induction: drawing a generalization based on individual instances.

David Hume (1748) has established that in order for induction to work, we have to assume that the world is uniform, in the sense that future events resemble past and present ones. Even if we have observed the sun rising every 
morning, from the beginning of time, this does not provide evidence that it will also rise tomorrow: we can conclude this only if we assume that the future will resemble the past.

Although this assumption is probably not warranted in general, when statisticians infer probabilities, they have to make the methodological assumption that the future resembles the past. In other words, they assume that the world we live in is uniform.

Based on this idea, I propose that generics are evaluated with respect to a uniform ordering source: an ordering source that prefers worlds whose future resembles their past. Thus, $w_{1} \leq w_{2}$ means that $w_{1}$ is more uniform than $w_{2}$.

As usual, future and past are determined relative to the reference time: generics are evaluated with respect to an ordering source that places a constraint on the future of worlds: the time after the reference time resembles the time before it. A natural thing to ask is whether generics also place requirements on what happens before the reference time. This, I suggest, is determined by the modal base, which deserves more careful consideration than it usually receives.

Condoravdi (2001) considers worlds to be complete histories through time. Two worlds are historical alternatives if they have the same past but possibly different futures. She defines a metaphysical modal base, which is the set of historical alternative to the actual world.

I suggest that generics are evaluated with respect to a metaphysical modal base and a uniform ordering source. In other words, they are evaluated with respect to those worlds among the metaphysical alternatives to the actual world that are preferred by a uniform ordering source. I call such worlds uniform worlds.

Uniform worlds share the history of the actual world up to the reference time. But from this point on, no significant change occurs: the future resembles the past. In such worlds it is true that "There is no new thing under the sun" (Ecclesiastes 1:9).

Hence, uniform worlds retain the stable properties of the actual world: non-stable properties will change in the actual world, but will remain the same in a uniform world.

Note that, crucially, uniform worlds are not normal worlds. Uniform worlds do not change, whereas normal worlds do change, albeit in ways that are lawlike and follow the essential nature of things.

Hence, normal worlds retain the essential properties of the actual world: non-essential properties may be different in a normal world.

Which theory is correct? Are generics evaluated with respect to normal or uniform worlds? This question should, and can, be settled empirically. 


\subsection{Empirical considerations}

The decision between the two theories is not a matter of taste: it is an empirical question. The two theories make different predictions. According to the normal theory, generics are sensitive to what happens in worlds in which essential properties of the actual world are preserved. According to the uniform theory, generics are sensitive to what happens in worlds in which stable properties of the actual world are preserved.

Let us first convince ourselves that generics are sensitive to stable properties. The following example is due to Carlson (1989):

(19) A computer computes the daily weather forecast. (Carlson 1989)

Carlson says (p. 179):

"the daily weather forecast" requires an intensional interpretation, where its meaning cannot be taken as rigidly referring to the present weather forecast, e.g. the one appearing in today's copy of the Times predicting light rain and highs in the upper thirties.

To see that this is indeed the case, suppose today's weather forecast predicts a severe blizzard, and is consequently the main news item. However, we cannot conclude (20) from (19).

(20) A computer computes the main news item.

The reason is that being the main news item is not a stable property of the weather forecast: on other days the weather forecast will not be the main news item.

Note that being the main news item is also not an essential property of the weather forecast. One might, therefore, claim that generics are sensitive to essential, rather than stable properties, and that this is the reason why (20) does not follow from (19). However, it can be easily shown that generics are not sensitive to essential properties.

Suppose the weather report is John's favorite newspaper feature in the actual world. Liking the weather report is a stable property of John, since such preferences do not change quickly. However, it is not an essential property of John, under any conceivable conception of essences. Hence, worlds in which he is not interested in the weather are perfectly normal. And yet, from (19) we can conclude:

(21) A computer computes John's favorite newspaper feature.

My claim that generics are not sensitive to essential properties is an important one, as it provides a powerful argument against the normality approach. Hence, 
it requires further evidence to substantiate it. As it happens, such evidence is easily obtained.

Suppose John fears all bats but no other animal. This is a stable property of John, but not an essential one. Hence, worlds where he likes bats are perfectly normal. And yet (22a) and (22b) have the same truth value:

(22) a. Bats fly.

b. Animals that John fears fly.

For another example, consider the fact that, in the actual world, the whale is the largest animal on earth. This is a stable property of the whale, but not an essential property: perhaps being large is an essential property of the whale, but it's a contingent fact that no larger animal exists. And yet, (23a) and (23b) have the same truth value.

(23) a. The whale suckles its young.

b. The largest animal on earth suckles its young.

The final example involves the quetzal, which is Guatemala's national bird. This is a stable property of this bird (the designation of a national bird remains for a long time, presumably forever), but this is not an essential property of the quetzal. And yet (24a) and (24b) have the same truth value.

(24) a. The quetzal has a magnificent, golden-green tail.

b. Guatemala's national bird has a magnificent, golden-green tail.

From all of the above we can conclude that the ordering source is uniform, not stereotypical, and that generics are evaluated with respect to uniform worlds, not normal ones.

\section{Generics as probability measures over uniform worlds}

We can now characterize generics in terms of the three components of modality. Their modal base is metaphysical - worlds that share the history of the actual world. The ordering source is uniform - it prefers worlds that do not change. And the modal force is a measure of high probability.

Thus, (2b) means that a pair $\langle b, w\rangle$, where $b$ is a bird and $w$ is a world that shares the history of the actual world, and whose future resembles the past, is likely to be such that $b$ flies in $w$. In other words: for a relatively long period of time it has been the case that most birds flew, and this pattern is expected to continue.

This view of generics explains how observations in the actual world affect the truth value of a generic, but do not determine it. In contrast, this fact is a problem for the normality approach, because it only considers normal 
worlds, so what happens in the actual world, which is not normal, should not affect the truth of a generic.

We can now provide a natural solution to the generic paradox. Generics are lawlike, because laws are stable properties. Sentence (1b) is odd because in the future, it is expected that new judges will be appointed, whose Social Security number will not be prime.

Generics tolerate exceptions, because they require high probability, but do not require that the value of this probability be equal to 1 .

To recap the main points of this paper: generics do not express universal quantification over normal worlds. Rather, generics quantify over worlds that resemble the actual world at the reference time, but do not evolve further. The quantificational force over such worlds is not universal, and can most naturally be formalized as a probability function. Using an extended probability logic, this system accounts for several problems of reasoning with generics and embedded generics. And , last but not least, it provides a solution to the generic paradox.

\section{REFERENCES}

Bacchus, Fahiem (1990). Representing and Reasoning with Probabilistic Knowledge. Cambridge, Massachusetts: MIT Press.

CARLSON, Greg (1989). On the semantic composition of English generic sentences. In Chierchia et al:: 167-192.

Chierchia, Gennaro; Partee, Barbara Hall; Turner, Raymond (eds.) (1989). Properties, Types and Meaning. Dordrecht: Kluwer.

Conen, Ariel (1996). Think Generic: The Meaning and Use of Generic Sentences. Doctoral dissertation, Carnegie Mellon University. Published 1999, Stanford: CSLI.

CoHen, Ariel (1999). Generics, frequency adverbs and probability. Linguistics and Philosophy 22: 221-253.

Condoravdi, Cleo.(2001). Temporal interpretation of modals: Modals for the present and for the past. In Beaver, D.; Casillas, L.; Clark, B. \& Kaufmann, S. (eds.) The Construction of Meaning: 59-88. Stanford, CA: CSLI Publications.

DAHL, Östen (1975). On generics. In Keenan, E. L. (ed.) Formal Semantics of Natural Language: 99-111. Cambridge: Cambridge University Press.

GaIfMAN, Haim (1988). A theory of higher order probabilities. In Skyrms, B. \& Harper, W. L. (eds.) Causation, Chance, and Credence, Vol. 1: 191-219. Dordrecht: Kluwer.

Gallin, Daniel (1975). Intensional and Higher-Order Modal Logic with Applications to Montague Semantics. Amsterdam: North-Holland.

HALPERn, Joseph Y. (1990). An analysis of first-order logics of probability. Artificial Intelligence 46: 311-350.

Hume, David (1748). An Enquiry Concerning Human Understanding. London: A. Millar.

KrATZER, Angelika (1981). The notional category of modality. In Eikmeyer, H. J. \& Rieser, H. (eds.) Words, Worlds, and Contexts: New Approaches to Word Semantics: 38-74. Berlin: de Gruyter. 
Kratzer, Angelika (2009). Modality in context. Context and Content Lectures, Paris.

KRIFKA, Manfred (2001). Quantification into question acts. Natural Language Semantics 9: 1-40.

Moltmann, Friederike (1995). Exception sentences and polyadic quantification. Linguistics and Philosophy 18: 223-280.

Nickel, Bernhard (2010). Generic comparisons. Journal of Semantics 27: 207-242.

PeArl, Judea (1988). Probabilistic Reasoning in Intelligent Systems: Networks of Plausible Inference. San Mateo: Morgan Kaufmann.

PeArl, Judea (1991). Probabilistic semantics for nonmonotonic reasoning. In Cummins, R. \& Pollock, J. (eds.) Philosophy and AI: 157-187. Cambridge, Massachusetts: MIT Press.

Pelletier, Francis Jeffrey, and Asher, Nicholas (1997). Generics and defaults. In van Benthem, J. \& ter Meulen, A. (eds.) Handbook of Logic and Language: 1125-1177. Amsterdam: Elsevier.

Schubert, Lenhart K. \& Pelletier, Francis Jeffry (1989). Generically speaking, or using discourse representation theory to interpret generics. In Chierchia et al. (1989): 193268.

ZuBER, Richard (1998). On the semantics of exclusion and inclusion phrases. In Lawson, A. (ed.) Proceedings of the 8th Conference on Semantics and Linguistic Theory: 267283. Ithaca, NY: Cornell University Press.

ZuBER, Richard (2004). Boolean semantics and categorial polyvalency. In Chand, V.; Kelleher, A.; Rodriguez, A; \& Schmeiser, B. (eds.) Proceedings of WCCFL 23: 829842. Somerville, MA: Cascadilla Press. 


\section{RÉSUMÉ}

On conçoit couramment les génériques comme exprimant une quantification universelle sur des individus normaux. Je réfute cette approche et démontre que la quantification n'est ni universelle ni sur des individus normaux.

Concernant l'universalité, les génériques ne répondent pas aux tests standards de la quantification universelle. Je propose, comme alternative, que les génériques expriment des mesures de haute probabilité. Je formalise cette notion au moyen d'une extension modale de la logique probabiliste du premier ordre, et montre comment ce système peut rendre compte des génériques enchâssés et des inférences sur des génériques.

Quant à la normalité, je la mets en contraste avec une autre notion, celle d'uniformité: les génériques sont évalués par rapport à des mondes dont le futur ressemble à leur passé. En utilisant les tests standards de substitution pour l'intensionnalité, je démontre que les génériques sont évalués par rapport à des mondes uniformes plutôt que normaux.

Le résultat final est qu'un générique comme Birds fly (les oiseaux volent) ne signifie pas «tous les oiseaux normaux volent»; il signifie plutôt que la probabilité pour qu'un oiseau pris au hasard vole est élevée, et qu'il est attendu que cette tendance perdure.

\section{Mots-CléS}

Génériques, modalité, normalité, source d'ordre uniforme, base modale métaphysique, probabilité, inférence, génériques enchâssés. 
